Original article

https://www.journal-imab-bg.org

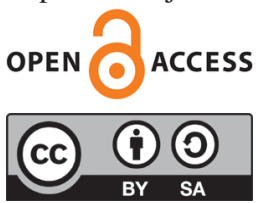

\title{
HEALTH RISK FACTORS: BODY MASS INDEX, BLOOD PRESSURE AND BLOOD GLUCOSE AMONG ROMA IN BULGARIA
}

\author{
Mariela Kamburova \\ Department of Public Health Sciences, Faculty of Public Health, Medical Uni- \\ versity - Pleven, Bulgaria.
}

\begin{abstract}
Roma communities suffer from higher rates of diabetes, cardiovascular disease, hypertension and related impairments and limitations in daily activities.

Purpose of the article is to study and analyze health risk factors: body mass index, blood pressure and blood glucose among the Roma population in small cities in Bulgaria.

Material/Methods: In May 2015, a communitybased approach was applied, and all adult residents of the Roma neighborhood of the town of Knezha, district of Pleven, were invited to participate. Only the persons who agreed to participate (59) or about $9 \%$ of the adult residents of Roma origin are included.

By measuring BMI, blood pressure and blood glucose, the collection of primary data was done.

The statistical processing of the data with Microsoft Office Excel 2010 and STATGRAPHICS-19 centurion software packages was performed. The significance of the results and conclusions was determined at $\mathrm{p}<0.05$.

Results: The Roma population is characterized by an unfavorable risk constellation and a health profile. Over two thirds $(77.1 \%)$ of the participants in the study have BMI values above the normal. There is a high relative share of people with hypertension $-42.3 \%$ of Roma people covered. Elevated levels of blood sugar were found in almost $40 \%$ of the people observed: in equal relative shares are presented the persons with impaired glucose tolerance (prediabetic) and diabetes mellitus - respectively $18.7 \%$.

Conclusions: The study found a wide distribution of unhealthy factors of lifestyle among Roma population, and particularly alarming results are established regarding to the health of the Roma women.
\end{abstract}

Keywords: Roma health, risk factors, communitybased approach,

\section{INTRODUCTION}

Worldwide, the size of Roma population is about 1012 million people. About 6 million live in the E.U., where they represent the largest ethnic minority, ranging from $9.9 \%$ of the population in Bulgaria, $9 \%$ in Slovakia and $8.6 \%$ in Romania to $0.1 \%$ in Germany and $0.2 \%$ in Italy

Bulgaria is one of the countries with the largest
Roma population. According to the 2001 census, 370,908 people identified themselves as Roma, and according to the 2011 census - 325,343 people, $44.13 \%$ of whom live in villages $[1,2]$. At the same time, international and Bulgarian researchers estimate the number of Roma in Bulgaria at about 800,000.

Research on infectious diseases among the Roma population has been the focus of public health for many years, although most research has recently focused on noncommunicable diseases, chronic diseases and related risk factors [3].

A number of studies report that Roma communities suffer from higher rates of chronic disease (asthma, diabetes, cardiovascular disease, hypertension) and related impairments and limitations in daily activities. The relationship between higher levels of chronic diseases and the higher prevalence of risk factors such as diet, physical activity, stress, as well as difficult access to primary health care and preventive health programs among Roma is discussed [4].

Data from 2011 show that the health status of Roma does not differ from that of the non-Roma sample. According to the results, $17 \%$ of Roma have suffered from one or more chronic diseases, while for non-Roma, this share is $18 \%$. The study reported a significantly higher proportion (70\%) of Roma over 65 suffering from chronic diseases than $56 \%$ of non-Roma [5].

Two scientific reviews of the literature on the problem have found increasing evidence of higher cardiovascular risk among Roma in Central and Eastern Europe and Italy $[6,7]$.

In a study of the prevalence of the metabolic syndrome and its components, conducted in a representative random sample $(n=646)$ of the Roma population aged 2064 living in segregated communities and a representative sample $(n=1819)$ of the Hungarian population, it was reported that the risk of central obesity, hypertension and a higher level of triglycerides among adult Roma does not differ from that of the Hungarian population, but elevated fasting serum glucose or type 2 diabetes mellitus $(\mathrm{OR}=2.64$, 95\% CI 1.89-3.68) and metabolic syndrome ( $\mathrm{OR}=1.37$, 95\% CI 1.03-1.83) are more common among Roma [8].

Diabetes risk studies in southern Slovakia, Serbia, and Hungary found a higher incidence rate among the 
Roma than in the general population $[9,10,11]$. They are also more likely to be obese and overweight, up to 2.5 times more likely than the non-Roma group [12, 13].

In the European Survey on Health and the Roma Community (2009), the Roma population estimates their health status as better - 2.19, compared to the EU-27 population - 2.25 [13].

Compared to the Roma from other European countries, the Roma in Bulgaria assesses their own health status as the worst -2.4 out of 5 possible points [13].

\section{PURPOSE}

To study and analyze health risk factors: body mass index, blood pressure and blood glucose among Roma population in small cities in Bulgaria.

\section{MATERIAL AND METHODS}

In May 2015, a community-based approach to conducting health surveys among vulnerable groups has been applied, in which the purpose, methodology and conduct of the survey have been discussed, planned and developed jointly with representatives of the Roma community in the town of Knezha. All adult residents of the Roma neighborhood of the town of Knezha, district of Pleven, were invited to participate. Only the persons who agreed to participate (59) or about $9 \%$ of the adult residents of Roma origin are included [2].

The collection of primary information was done by clinical examination and measuring of:

\section{Height in centimeters;}

\section{Weight in kilograms;}

An online calculator for calculation of a body mass index (BMI) according to age and gender was used.

The evaluation of the BMI was performed on the following scale:

- Below the norm: below $19 \mathrm{~kg} / \mathrm{m} 2$;

- Norm: 19 - $25 \mathrm{~kg} / \mathrm{m} 2$;

- Overweight: 25 - $30 \mathrm{~kg} / \mathrm{m} 2$;

- Obesity: over $30 \mathrm{~kg} / \mathrm{m} 2$.

3. Blood pressure in $\mathrm{mmHg}$ in a sitting position;

Blood pressure was measured according to the requirements of the European Society of Hypertension Guidelines Committee [14], and the WHO classification of hypertension was applied:

- Norm: below 129 at $84 \mathrm{mmHg}$;

- High: from 130 to 85 to 139 to $89 \mathrm{mmHg}$;

- Hypertension: over 140 to $90 \mathrm{mmHg}$.

\section{Fasting blood sugar levels in mmol/l.}

The measurement was performed with a glucometer through factory strips, and the WHO Diagnostic Criteria for Diabetes (2006) were applied [15]:

- Norm: up to $6.0 \mathrm{mmol} / \mathrm{l}$;

- Prediabetic: 6.1-7.0 mmol/1;

- Diabetic: over $7 \mathrm{mmol} / \mathrm{l}$.

The statistical processing of the primary data with Microsoft Office Excel 2010 and STATGRAPHICS-19 centurion software packages was performed.

Parametric tests were applied to test hypotheses in normal and close to the normal distribution of cases: t-test,
ANOVA and nonparametric tests in different than normal distribution of cases: chi-squared test, Mann-Whitney, Kruskal-Wallis H- test.

The significance of the results and conclusions was determined at $\mathrm{p}<0.05$.

The results are described by tables, graphs and numerical indicators for structure, frequency, averages, correlation coefficients, etc.

Permission to conduct the research was obtained from the Commission for Ethics of Research at the Medical University - Pleven.

\section{RESULTS}

Table 1 presents demographic characteristics of the sample of adults of Roma origin, residents of the town of Knezha, district of Pleven, Bulgaria.

Table 1. Distribution of the participants according to sex, age, education and employment

\begin{tabular}{|c|c|c|}
\hline Characteristics & Number & \% \\
\hline Sex & 59 & 100 \\
\hline Woman & $\mathbf{3 8}$ & $\mathbf{6 4 , 4}$ \\
\hline Man & 21 & 35,6 \\
\hline Age group & 59 & 100 \\
\hline $18-39$ age & 15 & 25,4 \\
\hline 40 - 64 age & $\mathbf{2 4}$ & $\mathbf{4 0 , 7}$ \\
\hline Over 65 years & 20 & 33,9 \\
\hline Education & 59 & 100 \\
\hline Less than 4 years & $\mathbf{2 2}$ & $\mathbf{3 7 , 3}$ \\
\hline 4 to 8 years & 15 & 25,4 \\
\hline More than 8 years & 22 & 37,3 \\
\hline Employment & 59 & 100 \\
\hline Unemployed & $\mathbf{2 3}$ & $\mathbf{3 8 , 9}$ \\
\hline Employed & 9 & 15,3 \\
\hline Retirees & $\mathbf{2 7}$ & $\mathbf{4 5 , 8}$ \\
\hline
\end{tabular}

\section{Body mass index (BMI)}

In fig. 1, data on the distribution of the covered persons according to BMI presents.

Fig. 1. Distribution of the participants by BMI

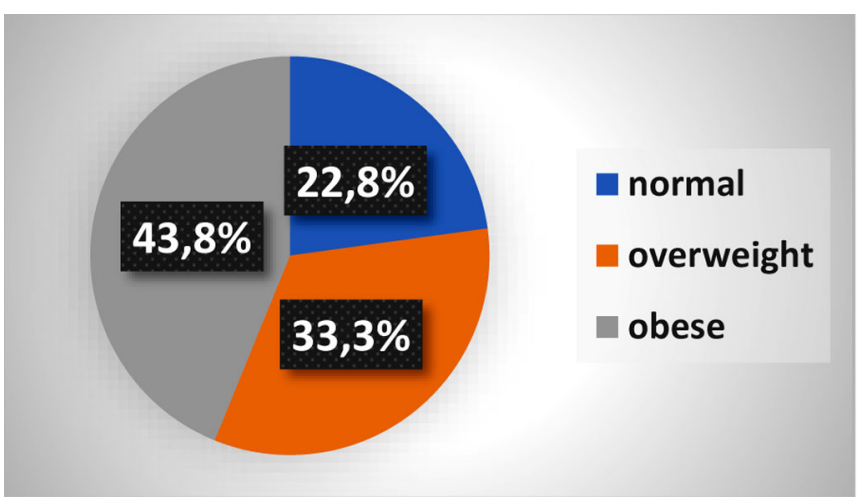


Over two thirds $(77.1 \%)$ of the participants covered have BMI values above the norm, $43.8 \%$ of them are persons with BMI over $30 \mathrm{~kg} / \mathrm{m} 2$ (obesity), and $22.8 \%$ of the persons covered in the study have normal BMI indicators.

There is a higher prevalence of obesity among Roma women, while among men, there is a wider prevalence of BMI above normal $\left(\chi^{2}=6.44 ; d f=2 ; p<0.05\right)$.

Age is a significant factor for BMI of persons of Roma origin $\left(\chi^{2}=14.17 ; d f=4 ; p<0.01\right)$. Among the age group 1839 years, people with normal weight predominate $(57.2 \%)$. The frequency of overweight increases with age. In the age group 40-65 years, $37.5 \%$ are overweight, and half of the persons are obese $(50 \%)$. Almost $90 \%$ of people over 65 have weight problems - respectively above the norm (47.4\%) and obese $(42.1 \%)$.

While the education of individuals does not have a significant impact on their BMI $(p>0.05)$, the presence of work plays a significantly significant role $\left(\chi^{2}=13.78\right.$; $d f=4$; $p<0.01)$. The relative share of working people in the study group who are obese is seven times higher than that of working people with normal weight, and the share of pensioners with normal weight is over three times lower than that of pensioners with obesity. Among the unemployed, the share of those with normal BMI values prevails $-39.1 \%$.

\section{Blood/blood pressure}

There is a high relative share of people with hypertension $-42.3 \%$ of those covered. The predominant part (44.1\%) of the representatives of the Roma ethnic group have normal blood pressure, and $13.6 \%$ have high values (fig. 2).

Fig. 2. Distribution of the participants by BMI

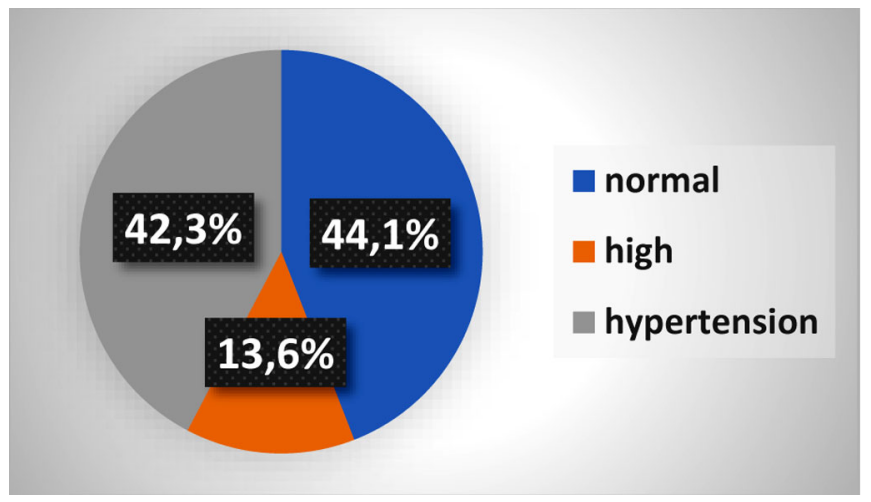

It was found to be higher than the usual effect of age on blood pressure $\left(\chi^{2}=10.45 ; d f=4 ; p<0.01\right)$. Among the persons in the young age group, the share of those with normal blood pressure values prevails (73.3\%), while among the covered persons over 65 - that of the persons with A.H. (60\%). Of particular concern is the distribution of individuals with high blood pressure or prehypertension, which is most likely not controlled and treated. $20.8 \%$ of people in the age group 40-65 have high blood pressure, and their share is over 4 times higher than that of people over 65 with high blood pressure $(5 \%)$.

Education has a significant effect on $\mathrm{BP}\left(\chi^{2}=10.26\right.$; $d f=4 ; p=0.02)$.In the majority of those surveyed with primary and lower education, hypertension was found (54.6\%), while among the other two compared groups with hypertension were as follows: in persons with primary education, $33.3 \%$, and in those with higher education $-36.4 \%$. Among those with primary and higher education, those with normal blood pressure predominate $-46.7 \%$ and $63.6 \%$, respectively.

The presence of work is not a significant factor for the values fof B.P. in our study $(p>0.05)$.

The study examined the influence of health determinants - gender, age, education and employment status on diastolic blood pressure. We found a significant influence of age over diastolic pressure $\left(\chi^{2}=13.28\right.$; $d f=4$; $p=0.01$ ), but this has not been demonstrated for gender, educational, and employment status of the persons covered $(p>0.05)$.

\section{Blood sugar/serum glucose}

When screening for blood sugar levels, among the residents of Roma origin from the town of Knezha, elevated levels of the indicator were found in almost $40 \%$ of the covered: in equal relative, shares are presented the persons with impaired glucose tolerance and diabetes mellitus $18.7 \%$ respectively (table 2 ).

Table 2. Distribution of the participants according to blood sugar levels

\begin{tabular}{|c|c|c|c|c|}
\hline \multirow{3}{*}{ Characteristic } & \multirow{3}{*}{$\begin{array}{c}\text { Number of people } \\
\text { covered }\end{array}$} & \multicolumn{3}{|c|}{ Blood sugar/serum glucose } \\
\hline & & Normal & Prediabetic & Diabetic \\
\hline & & up to $6,0 \mathrm{mmol} / \mathrm{l}$ & $6,1-7,0 \mathrm{mmol} / \mathrm{l}$ & over $7 \mathrm{mmol} / \mathrm{l}$ \\
\hline \multicolumn{5}{|c|}{$\operatorname{Sex}(p>0,05)$} \\
\hline Woman & 38 & 64,9 & 55,5 & 63,7 \\
\hline Man & 21 & 35,1 & 45,5 & 27,3 \\
\hline Total & 59 & 100 & 100 & 100 \\
\hline \multicolumn{5}{|c|}{ Age $\left(\chi^{2}=11,12 ; d f=4 ; p=0,02\right)$} \\
\hline $18-39$ age & 16 & 40,6 & 9,1 & 0 \\
\hline
\end{tabular}




\begin{tabular}{|c|c|c|c|c|}
\hline $40-64$ age & 24 & 29,7 & 63,6 & 45,5 \\
\hline Over 65 years & 19 & 29,7 & 27,3 & 54,5 \\
\hline Total & 59 & 100 & 100 & 100 \\
\hline \multicolumn{5}{|c|}{ Education $\left(\chi^{2}=9,59 ; d f=4 ; p=0,04\right)$} \\
\hline Less than 4 years & 23 & 29,7 & 27,3 & 72,7 \\
\hline 4 to 8 years & 15 & 24,4 & 45,5 & 9,1 \\
\hline More than 8 years & 21 & 45,9 & 27,2 & 18,2 \\
\hline Total & 59 & 100 & 100 & 100 \\
\hline \multicolumn{5}{|c|}{ Employment $(p>0,05)$} \\
\hline Unemployed & 23 & 43,2 & 45,5 & 18,2 \\
\hline Employed & 9 & 21,6 & 9 & 0 \\
\hline Retirees & 27 & 35,2 & 45,5 & $\mathbf{8 1 , 8}$ \\
\hline Total & 59 & 100 & 100 & 100 \\
\hline
\end{tabular}

While the gender and employment status of the Roma persons covered do not have a statistically significant effect on blood sugar levels $(p>0.05)$, age $\left(\chi^{2}=11.12\right.$; $d f=4 ; p=0.02)$ and the educational degree $\left(\chi^{2}=9.59 ; d f=4\right.$; $p=0.04$ ) have.

\section{DISCUSSION}

Studies of the health status of the Roma show a close connection with the social determinants of health. Many of these factors act in a complex and combined way on people living in disadvantaged conditions [16].

Being overweight, one of the components of metabolic syndrome is one of the leading risk factors for socially significant diseases globally and nationally [17]. A study in Bulgaria, within the CINDY program, in 2007 on men and women of active age shows that $45.9 \%$ of men and $30.7 \%$ of women are overweight, and $24.6 \%$ and $24.4 \%$ are obese, respectively [18].

Similar results, but lower than the data established by us, for overweight or obesity in 70.2\% (1375/1958) of the surveyed Bulgarians, reported in a representative study by Borisova et al. [19]. In our study, the share of people from the Roma ethnic group with obesity is one third higher than found by the author, namely $44 \%$, and the results are higher than reported in a study in Bulgaria under the CINDY program in 2007.

Weight is strongly influenced by the demographic characteristics of individuals. According to Borisova et al. [19], among the Bulgarian ethnic group in women, obesity and overweight are significantly less common than men, and vice versa, women, are about twice as likely to have a normal body weight compared to the opposite sex [20]. According to other authors, about $51 \%$ of women in our country are overweight and obese, and this alarming statistic puts Bulgaria in 5th place in Europe in terms of overweight [21, 22].

While some studies report that the Roma population is genetically less susceptible to essential hypertension than the general population [24], the results of our study coincide with the reported higher levels of hypertension in the Balkan countries and Bulgaria - an aver- age of about $38-44 \%$ [20].

Our study does not confirm what was reported by Borisova et al. [20], in a representative for the country study, distribution of hypertension between the two sexes in the Bulgarian population: significantly higher frequency in men $45.1 \%$ compared to women $-33.5 \%$. A representative study for the country, within the CINDY program (1997-1998), reported an incidence of hypertension $(\geq 140 / 90 \mathrm{mmHg}$ ) in $43.0 \%$ of men and $39.0 \%$ of women aged 25-64 years. A study again under the same program in 2007 found hypertension ( $\geq 140 / 90 \mathrm{mmHg}$ ) in every 3rd man and every 4th woman at that age.

Our study found a higher prevalence of hypertension in women - $44.7 \%$ compared to men $-38.1 \%$ $(p>0.05)$. The observed differences are most likely due to the self-formation of the sample, which is characterized by a higher relative share of women.

The results established in the present study indicate a wider prevalence of hypertension among the different age groups of the Roma population compared to the Bulgarian, respectively $13.3 \%$ vs $9.3 \%$ among the young (18-39 years old people), $45.8 \%$ vs $12.3 \%$ for the 40-64 age-old people and 60\% compared to $17.4 \%$ among the elderly people [20].

Diabetes is a disease that is defined as socially significant. In Bulgaria, the number of patients is about 350,000 , but it is estimated that the actual number of people affected is about 600,000 . According to results reported in a representative study for the country by Borisova [23], diabetes in the country has a frequency of $9.6 \%$ (diagnosed $-7.1 \%$ and undiagnosed $-2.5 \%$ ), and prediabetes $-3.7 \%$ (impaired glucose tolerance - $1.6 \%$ and impaired glycemia of fasting $-2.1 \%$ ) and the incidence of diabetes in Bulgaria fully corresponds to a country with low to medium gross domestic product. The incidence of diabetes is significantly higher in men than in women $-56.7 \%$ of diabetic men versus $43.3 \%$ of diabetic women $(\mathrm{p}<0.001)[23]$.

In most cases, the diagnosis of type 2 diabetes is made very late, on average 5 years after the onset of the disease, when there are already vascular complications of 
high blood sugar, which provokes interest in our blood glucose screening of the subjects.

According to our data, people with impaired glucose tolerance are mostly middle-aged women with primary education, unemployed or retired, while the profile of people with diabetes is formed mainly by women over 65 , without or with primary education and retirees (table. 2).

Our results are particularly worrying with regard to the health of Roma women, namely: a higher proportion and incidence of obesity, a higher incidence of hypertension and a higher risk of developing diabetes, which puts them in a situation of increased risk of developing socially significant diseases.

\section{STUDY}

STRENGTHS AND LIMITATIONS OF THE

Scientific studies of the health status of the Roma population in Bulgaria are conducted relatively rarely. The present study enriches the data on the problem.

The internal validity of a study can be threatened by many factors, including errors in measurement or in the selection of participants in the study. One of the weaknesses of the study is that the sample was self-formed by voluntarily involved residents of the town of Knezha. This fact does not allow the study to claim external validity of the results.

\section{CONCLUSION}

The Roma population is characterized by an unfavorable risk constellation and a health profile. The study found a wide distribution of unhealthy factors of lifestyle among the Roma population, and particularly alarming results are established regarding to health of the Roma women.

\section{REFERENCES:}

1. Final results of the census 2001. [in Bulgarian] NSI. 2001. [Internet]

2. [Census of the population and housing stock in the Republic of Bulgaria.] [in Bulgarian] NSI. 2011. [Internet]

3. Földes ME, Covaci A. Research on Roma health and access to healthcare: state of the art and future challenges. Int J Public Health. 2012 Feb;57(1):37-9. [PubMed]

4.Masseria C, Mladovsky $\mathrm{P}$, Hernández-Quevedo C. The socioeconomic determinants of the health status of Roma in comparison with non-Roma in Bulgaria, Hungary and Romania. Eur J Public Health. 2010 Oct;20(5):549-54. [PubMed]

5.Roma education in comparative perspective. Roma Inclusion Working Papers, UNDP Europe and the CIS, Bratislava Regional Centre. UNDP. 2012. [Internet]

6.Dobranici M, Buzea A, Popescu $\mathrm{R}$. The cardiovascular risk factors of the Roma (gypsies) people in CentralEastern Europe: a review of the published literature. J Med Life. 2012 Dec 15;5(4):382-9. [PubMed]

7.Monasta L, Erenbourg A, Restaino S, Lutje V, Ronfani L. Review of the Scientific Literature on the Health of the Roma and the Sinti. Ethn Dis. 2012 Summer;22(3):367-71. [PubMed]

8.Kosa Z, Moravcsik-Kornyicki A,
Dioszegi J, Roberts B, Szabo Z, Sandor J, et al. prevalence of metabolic syndrome among Roma: a comparative health examination survey in Hungary. Eur J Public Health. 2015 Apr;25(2):299-304. [PubMed]

9.Hidvegi T, Hetyesi K, Biro L, Nadas J, Jermendy G. Screening for metabolic syndrome within a minority ethnic group (adult Gypsy people) in Hungary. Bratisl Lek Listy. 2012;113(12):721-4. [PubMed]

10. Vozarova de Courten B, de Courten M, Hanson RL, Zahorakova A, Egyenes HP, Tataranni PA, et al. Higher prevalence of type 2 diabetes, metabolic syndrome and cardiovascular diseases in gypsies than in nongypsies in Slovakia. Diabetes Res Clin Pract. 2003 Nov;62(2):95-103. [PubMed]

11.Beljiæ Zivkoviæ T, Marjanoviæ M, Prgomelja S, Soldatovic I, Koprivica B, Ackoviæ $\mathrm{D}$, et al. Screening for diabetes among Roma people living in Serbia. Croat Med J. 2010 Apr;51(2):144-50. [PubMed]

12.Krajcovicova-Kudlackova M, Blazicek P, Spustova V, Valachovicova M, Ginter E. Cardiovascular risk factors in young Gypsy population. Bratisl Lek Listy. 2004; 105 (78):256-9. [PubMed]

13. Health and the Roma Community, analysis of the situation in Europe. Bulgaria, Czech Republic,
Greece, Portugal, Romania, Slovakia, Spain. Fundación Secretariado Gitano. Madrid. 2009. [Internet]

14.ESHESC Guidelines Committee. 2003 European Society of Hypertension-European Society of Cardiology guidelines for the management of arterial hypertension. J Hypertens. 2003 Jun;21(6):1011-53. [PubMed]

15.Tsvetkova T, Danev S. editors. [Analytical principles and procedures in the clinical laboratory.] [in Bulgarian] Plovdiv. Med. Publishing House Vasil Petrov - VAP. 2001.

16.Orton L, de Cuevas RA, Stojanovski K, Gamella JF, Greenfields M, La Parra D et al. Roma populations and health inequalities: a new perspective. Int $\mathrm{J} \mathrm{Hum} \mathrm{Rights}$ Healthc, 2019 Nov 28;12(5):319327. [PubMed]

17.Lu Y, Hajifathalian K, Ezzati M, Woodward M, Rimm EB, Danaei G. The Global Burden of Metabolic Risk Factors for Chronic Disease. Metabolic mediators of the effects of bodymass index, overweight, and obesity on coronary heart disease and stroke: a pooled analysis of 97 prospective cohorts with 1.8 million participants. Lancet. 2014 Mar 15;383(9921):97083. [PubMed]

18. Health status of citizens in 2009. Annual report. Ministry of Health. Sofia. 2010. [Internet]

19. Borisova A-MI, Shinkov AD, Vlahov JD, Dakovska LN, Todorov 
TC. [Study on the prevalence of obesity among the Bulgarian population in 2012.] [in Bulgarian] Endocrinology. 2015; 20(2):82-8. [Internet]

20. Borissova A-MI, Shinkov AD, Vlahov JD, Dakovska LN, Todorov TC. [Prevalence of arterial hypertension in Bulgarian population (actual data).] [in Bulgarian] Endocrinology. 2015; 20(2):76-81. [Internet]

21. Uchikova EH, Orbetzova İ̀̀. [Metabolic Syndrome, Obesity and Risk of Endometrial Carcinoma.] [in Bulgarian] Endocrinology. 2015; 20(2):69-75. [Internet]

22. Kaidar-Person O, Bar-Sela G, Person B. The two major epidemics of the twenty-first century: obesity and cancer. Obes Surg. 2011 Nov;21(11):1792-7. [PubMed]

23. Borissova A-MI, Shinkov AD, Vlahov JD, Dakovska LN, Todorov TC. [Prevalence of diabetes mellitus and prediabetes in Bulgaria today.] [in Bulgarian] Endocrinology. 2012; 17(4):182-192. [Internet]

Please cite this article as: Kamburova M. Health risk factors: body mass index, blood pressure and blood glucose among Roma in Bulgaria. J of IMAB. 2021 Oct-Dec;27(4):4014-4019. DOI: https://doi.org/10.5272/jimab.2021274.4014

Received: 23/04/2021; Published online: 06/10/2021

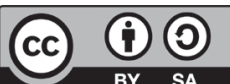

Address for correspondence:

Mariela Kamburova

Department of Public Health Sciences, Faculty of Public Health, Medical University - Pleven, Bulgaria

1, K1. Ohridski, str., Pleven 5800, Bulgaria

E-mail: mariela_kamburova@yahoo.com 